\title{
How do types of employment relate to health indicators? Findings from the Second European Survey on Working Conditions
}

\author{
F G Benavides, J Benach, A V Diez-Roux, C Roman
}

\begin{abstract}
Study objective-To investigate the associations of various types of employment with six self reported health indicators, taking into account the part played by demographic variables, individual working conditions and four ecological indicators at the country level.

Design-Cross sectional survey (structured interview) of a sample of the active population of 15 European countries aged 15 years or over. Main independent variables were nine types of employment categorised as follows: small employers, full and part time permanent employees, full and part time fixed term employees, full and part time sole traders and full and part time temporary contracts. Main outcome measures were three self reported health related outcomes (job satisfaction, health related absenteeism, and stress) and three self reported health problems (overall fatigue, backache, and muscular pains). Logistic regression and multilevel models were used in the analyses.
\end{abstract}

Setting-15 countries of the European Union.

Occupational Health

Research Unit,

Department of

Experimental Sciences and Health,

Universitat Pompeu

Fabra, Barcelona,

Spain

F G Benavides

J Benach

C Roman

Division of General Medicine, Columbia Presbyterian Medical Center, Columbia

University and

Division of

Epidemiology,

Columbia School of

Public Health, New

York, USA

A V Diez-Roux

Correspondence to: Dr Benavides, Department of Experimental Sciences and Health, Universitat

Pompeu Fabra, C/ Dr

Aiguader 80, 08003

Barcelona, Spain

(fernando.benavides@cexs. upf.es)

Accepted for publication 17 February 2000
Participants-15 146 employed persons aged 15 or over.

Main results-Precarious employment was consistently and positively associated with job dissatisfaction but negatively associated with absenteeism and stress (as compared with full time permanent workers). Fatigue, backache and muscular pains also tended to be positively associated with precarious employment, particularly with full time precarious employment. Small employers reported high percentages of stress and fatigue, but absenteeism was relatively low. Sole traders generally reported high percentages of all outcomes, except for absenteeism, which was low. For each type of employment (except temporary contracts), full time workers tended to report worse health outcomes than part time workers. Patterns were generally consistent across countries. Associations persisted after adjustment for individual level working conditions and were not modified by country level variables.

Conclusions-This study is the first to examine the relations between various types of employment and six health related indicators for all 15 member states of the European Union. Suggestive patterns worthy of further exploration have been found. Standardised definitions of types of underemployment and health related outcomes, more potent epidemiological designs and the inclusion of socioeconomic information (for example, social security systems, incapacity benefit schemes) at the regional level are proposed for inclusion in further research.

(F Epidemiol Community Health 2000;54:494-501)

In the two past decades an increasing number of studies have found that unemployment is strongly associated with adverse health indicators such as higher mortality, unhealthy symptoms, unfavourable lifestyles or more psychological problems at both individual and ecological levels. ${ }^{1-4}$ Although unemployment is likely to be one of the major long term social problems that Europe is facing, European countries are increasingly showing new forms of work organisation and flexible employment. These socioeconomic changes are leading to high numbers of various types of underemployment, including involuntary part time employment and insecure employment, together with high unemployment rates. ${ }^{5}$ In the European Union (EU), precarious employment (fixed term contracts and temporary work) accounts for $15 \%$ of paid employment. The highest percentages are found in Spain (40\%) and France $(22 \%)$ while the lowest levels are found in Luxembourg and Austria (9\%). ${ }^{6}$

Knowledge of the impact of these new forms of employment on health indicators is very scarce. ${ }^{2-9}$ An EU report found that employees with precarious contracts, and particularly temporary workers, were much more exposed to poor working conditions such as vibrations, loud noise, hazardous products or repetitive tasks. For example, temporary workers work more often than permanent workers in painful or tiring positions ( $57 \%$ compared with $42 \%$ ), are more exposed to intense noise $(38 \%$ compared with 29\%), and perform repetitive tasks more frequently (46\% compared with $36 \%) .^{5}$ In addition, preliminary studies at the national level have begun to analyse the effects of precarious work on some health outcomes and have suggested that new types of contracts may be linked to ill health. In Spain and France, for example, temporary workers showed much higher levels of occupational accidents as compared with permanent workers. $^{10} 11$

Many questions still remain unanswered regarding the potential associations between 
various types of employment and health, the part played by potential modifying variables such as individual (for example, age, gender) or environmental factors (for example, poor working conditions), and the potential buffering effects of various social factors (for example, social protection) at the country level. Data from the Second European Survey on Working Conditions linked to ecological data drawn from Eurostat provide an excellent opportunity to examine these questions for the first time in the 15 countries of the EU.

The two objectives of this study were: firstly, to assess the overall associations between types of employment and health indicators after taking into account the effects of several demographic variables and working conditions including both physical and psychosocial indicators; and secondly, to examine whether differences between precarious and permanent employments are modified by several ecological variables measured at the country level. ${ }^{12}$

\section{Methods}

PARTICIPANTS AND STUDY SAMPLE

The Second European Survey of Working Conditions was based on a representative sample of the total active population 15 years of age and over of the 15 countries of the EU. ${ }^{13}$ The total active population included all employed and self employed persons. Persons were classified as employed it they did any work for pay or profit during the reference week, or if they were not working but had jobs from which they were temporarily absent. All retirees, unemployed persons, and homemakers were excluded. Non-Europeans were included on the condition that they could be interviewed in the respective national language of the countries where they worked. The Survey was conducted in January 1996 using multi-stage random sampling. The actual number of interviews conducted was at least 1000 people per country (with the exception of Luxembourg where only 500 interviews were conducted) ranging from 1000 in Portugal, Spain and Denmark to 2087 in Germany (1053 for former East Germany and 1034 for former West Germany). The respondents were interviewed at home. The questionnaire consisted of 41 questions that covered information on types of contracts, various health outcomes and several aspects of working conditions including the physical environment, psychosocial working conditions, design of work stations, working hours, work organisation and social support at work. Questionnaires were completed by a total of 15986 workers. Response rates ranked by country were as follows: Austria $81 \%$, France $79 \%$, Spain $77 \%$, East Germany and Ireland $70 \%$, West Germany $67 \%$, Portugal and Sweden $66 \%$, Luxembourg $60 \%$, Belgium and United Kingdom 58\%, Finland 55\%, Greece $47 \%$, Italy $43 \%$, the Netherlands $37 \%$, Denmark 35\%. Altogether 840 subjects were excluded from the analysis because they were workers not performing a paid job in strict sense (for example, trainees, apprentices). Therefore, the final number of persons included in the analyses was 15146.
MEASURES

Three self reported health related outcomesjob satisfaction, sickness absenteeism, and stress-were used to assess the overall well being of employees. The health related outcomes were based on three different questionnaire items: job satisfaction ("on the whole, are you satisfied, fairly satisfied not very satisfied or not at all satisfied with your main job"), health related absenteeism ("over the past 12 months, how many days, if any, were you absent due to health problems caused by your main job?"), and stress ("Does your work affect your health or not?" If yes, "how does it affect your health?" Choose one or more of the following options. A list of 18 options including stress, fatigue, muscular pains, and backache followed.) All three items were dichotomised. Persons were classified as being dissatisfied with their job if they reported being "not very satisfied" or "not at all satisfied", and they were classified as high absenteeism if they reported being absent one or more days over the past year. Participants were classified as reporting stress if they reported that their work affected their health and chose stress as one of the reasons.

Three self reported health indicatorsoverall fatigue, backache, and muscular painwere also selected as outcomes based on their high prevalence in the EU as shown in two previous studies. ${ }^{6}{ }^{14}$ Participants were classified as reporting overall fatigue if they reported that their work affected their health and chose fatigue as one of the reasons; they were classified as reporting backache if they chose backache as one of the reasons; and they were classified as reporting muscular pain if they chose muscular pain in arms or legs as one of the reasons.

The main independent variable investigated was type of employment classified into nine categories as follows: full and part time permanent employment, full and part time fixed term employment, full and part time temporary employments, full and part time sole traders (self employed with no employees), and small employers (employers employing between one and nine people). These categories were based on participant responses to the following questions: (a) "Are you mainly self employed, employed on a permanent basis, employed on a fixed term contract, or employed on a temporary employment agency contract?" and (b) "How many hours do you usually work per week, in your main job?". Participants responding that they were self employed were classified into sole traders (no employees) and small employers (1-9 employees) based on their responses to a subsequent question on number of employees. Based on standard definitions of part time work, participants were classified as part time if they reported working less than 35 hours per week.

Analyses pooling all countries used all nine categories with those in full time permanent employment as the reference. Because of sample size limitations, country specific analyses were based on four categories: permanent employments (full and part time combined), small employers, sole traders (full and part 
time combined) and precarious employments (including all fixed term and temporary employments). Permanent employment was the reference category for the country specific analyses. Only results for precarious employments compared with permanent employments are reported in the country specific and multilevel analyses.

Covariates investigated included age in years, gender, company size (1 to 9,10 to 499 , 500 and over), work shifts (Yes/No), six dichotomised physical variables (exposure to vibrations, loud noise, and extreme temperatures; breathing in vapours or fumes; performing short repetitive tasks and repetitive hand or arm movements), and three variables reflecting the psychosocial work environment (control, demand and social support) (see table 1). The questionnaire items did not directly correspond to any of the routine scales used to characterise the psychosocial work environment. However, they were grouped into the three dimensions based on their face validity and similarity to questions used in other standard scales. Social support at work was assessed using a single question. Details of those measures have been reported elsewere. ${ }^{14}$

The field work was conducted by INRAEUROPE, which translated questionnaires to the different European languages and standardised the interview procedures.

Country level variables related to the economic and employment situation in the country as a whole may modify the relation between type of employment and health indicators, either by buffering or increasing the effect of type of employment on health. In these analyses, we included information on four ecological variables at the country level obtained from the 1995 Eurostat files. Selection of ecological variables was based on two criteria: (1) the potential relevance of the variable from a theoretical perspective, and (2) the availability of information on the variable for all European countries. Four variables were chosen as indicators of country context: unemployment (annual average rate), ${ }^{15}$ per cent of temporary contracts (out of the total number of contracts), ${ }^{16}$ social protection benefits (percentage of Gross Domestic Product at market price), ${ }^{17}$ and Gross National Product per capita (Purchasing Parity power (PPP)). ${ }^{18}$

\section{KEY POINTS}

- Precarious employment was associated with job dissatisfaction, but negatively associated with reported stress and absenteeism. Fatigue, backache and muscular pains were also more common in persons in full time precarious employment.

- Associations persisted after adjustment for individual level working conditions and were not modified by country level variables.

- Standardised definitions of types of underemployment, better categorisation of outcomes, and the inclusion of socioeconomic information at the regional level should be used in further research.

- The study of the potential effects of underemployment and precarious employment on health is a challenge for researchers.

\section{STATISTICAL ANALYSIS}

Logistic regression models were used to determine whether there were significant associations between nine or four types of employment used as independent variables, and each of the six health indicators taken as dependent variables. Multivariate models for each health indicator were built adjusting for age and gender in a first step and adding additional individual level covariates (see table 1) in a second step. Final estimates are presented adjusted only for age and gender because other individual level variables did not substantively modify the relation between type of employment and the health indicators studied. All models were examined pooling across countries (with nine employment categories) and also stratified by country (with four employment categories).

Multilevel models ${ }^{19}{ }^{20}$ were used to investigate and quantify (a) variability in the outcomes across countries (after controlling for type of employment and individual level variables) as well as variability in the effects of precarious employment across countries; and (b) the extent to which this variability is a function of the country level variables (that is, associations of country level variables with the outcome after controlling for types of employment as well as interactions between country level variables and type of employment). The

Table 1 Summary of measures

\begin{tabular}{|c|c|c|c|c|}
\hline Health indicators & Main variable* & & Variables at the individual level & Variables at the country level \\
\hline $\begin{array}{l}\text { Job dissatisfaction } \\
\text { Absenteeism } \\
\text { Fatigue } \\
\text { Stress } \\
\text { Backache } \\
\text { Muscular pains }\end{array}$ & $\begin{array}{l}\text { Permanent } \\
\text { Sole traders } \\
\text { Fixed term } \\
\text { Temporary } \\
\text { Small employers }\end{array}$ & $\begin{array}{l}\text { full time } \\
\text { part time } \\
\text { full time } \\
\text { part time } \\
\text { full time } \\
\text { part time } \\
\text { full time } \\
\text { part time }\end{array}$ & $\begin{array}{l}\text { Age } \\
\text { Gender } \\
\text { Company size } \\
\text { Work shifts } \\
\text { Vibration } \\
\text { Noise too loud } \\
\text { Extreme temperature } \\
\text { Breathing in vapours and fumes } \\
\text { Short repetitive tasks } \\
\text { Repetitive hand or arm movements } \\
\text { Psychosocial demand } \\
\text { Psychosocial control } \\
\text { Social support at work }\end{array}$ & $\begin{array}{l}\text { Unemployment } \\
\% \text { Temporary contracts } \\
\text { Social protection } \\
\text { Gross National Product }\end{array}$ \\
\hline
\end{tabular}

${ }^{\star}$ Because of sample size limitations only four categories were used in country specific analyses. 
Table 2 Distribution of employment categories and health outcome by country (percentages)

Great

Belgium Denmark Germany Greece Italy Spain France Ireland Luxembourg Netherlands Portugal Britain Finland Sweden Austria

Employment categories (\%)

Permanent employment

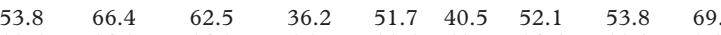

$\begin{array}{llllllllll}\text { Small employers } & 12.5 & 14.2 & 14.9 & 6.2 & 11.6 & 5.7 & 14.5 & 12.0 & 9.2 \\ \text { So } & 8.0 & 2.5 & 5.5 & 12.4 & 11.6 & 6.7 & 3.8 & 8.9 & 5.5\end{array}$

Sole traders

Full time

Part time

$\begin{array}{lllllllll}12.9 & 3.2 & 4.7 & 29.5 & 16.1 & 15.2 & 8.4 & 11.9 & 6.4\end{array}$

Precarious

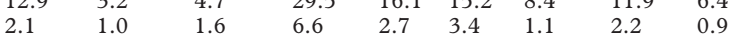

$\begin{array}{llllllllll}\text { Fixed term, full time } & 5.8 & 6.1 & 6.1 & 4.1 & 2.9 & 17.4 & 11.2 & 4.8 & 5.7\end{array}$

$\begin{array}{llllllllll}\text { Fixed term, part } & 2.5 & 2.4 & 3.6 & 1.7 & 1.1 & 3.9 & 5.5 & 2.8 & 0.4\end{array}$

time

$\begin{array}{llllllllll}\text { Temporary, full time } & 1.5 & 1.8 & 0.9 & 2.5 & 1.5 & 4.9 & 2.0 & 2.0 & 1.5 \\ \text { Temporary, part } & 0.9 & 2.4 & 0.2 & 0.8 & 0.8 & 2.3 & 1.4 & 1.6 & 0.7\end{array}$

time

Health outcomes (\%)
Job dissatisfaction

Job dissatisfaction

Absenteeism

Stress

Fatigue

Backache

$\begin{array}{lll}6.7 & 5.4 & 12.2\end{array}$

$\begin{array}{llllll}0.8 & 0.8 & 2.3 & 1.4 & 1.6 & 0.7\end{array}$

12.2

$\begin{array}{llllll}35.4 & 18.2 & 20.0 & 17.9 & 5.5 & 7.8\end{array}$

$\begin{array}{lllllllll}26.4 & 14.7 & 33.3 & 16.9 & 17.5 & 19.0 & 20.4 & 17.2 & 31.1 \\ 20.9 & 28.5 & 27.2 & 49.1 & 40.4 & 21.8 & 23.9 & 12.4 & 37.3\end{array}$

$\begin{array}{lllllllll}13.7 & 10.6 & 16.2 & 55.9 & 24.6 & 28.1 & 23.6 & 10.0 & 13.8\end{array}$

Muscular pains

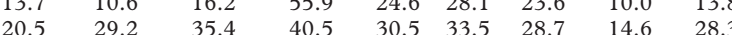

$\begin{array}{lllllllll}9.7 & 23.7 & 35.4 & 40.5 & 30.5 & 33.5 & 28.7 & 14.6 & 28.3 \\ 9.7 & 14.2 & 33.4 & 17.1 & 22.5 & 18.1 & 7.3 & 11.4\end{array}$

multilevel models were conceptualised as two level models. In the first stage (individual level) a regression model was defined for each country including the four employment categories plus all individual level variables. In the second stage (country level), country specific intercepts and the country specific regression coefficients corresponding to precarious employment were modelled as random across countries. Variability in outcomes across countries (after controlling for type of employment and individual level variables) and in the effects of precarious employment was quantified by the variances of the random effects. Country level variables were subsequently added to the second level models for the intercept and for the coefficient corresponding to precarious employment to determine whether they were independently associated with the outcomes or modified the effects of precarious employment on the outcomes. Initially each country level variable was investigated separately. Models were also fit including all country level variables simultaneously. Of the 15146 persons in the database, 3419 were excluded from the multilevel analyses because they were missing one or more of the individual level variables. There were no substantial differences between excluded and included participants. All analyses were performed using SPSS 7.5.2S $\mathrm{S}^{21}$ and HLM 3.0 programs. ${ }^{22}$

\section{Results}

Table 2 shows the distribution of type of employment and health outcomes by country. Workers employed with full time permanent contracts represented almost $56 \%$ of all jobs while part time permanent contracts accounted for almost $14 \%$, sole traders (full and part time together) and workers with precarious contracts (that is, all fixed term and temporary contracts) showed about $12 \%$ each, and small employers accounted for only $6 \%$ of the total. In Germany, Luxembourg, and the Nordic countries between $60 \%$ and $70 \%$ of the sample was in full time permanent employment, whereas small employers and full time sole traders accounted for small percentages of the total (2.5-7.5\%). Greece and Spain showed especially low levels of full time permanent employment. In Greece there was a high percentage of small employers and sole traders, and in Spain, a large percentage of the sample was in precarious employment. The health outcomes investigated also varied by country. The worst outcomes were found in Greece, Spain and Portugal while low percentages for most outcomes were observed in Ireland, Belgium and Netherlands.

The distribution of health indicators by employment for the 15 countries combined is presented in table 3. Overall, persons in precarious employments had higher rates of job

Table 3 Distribution of self reported health indicators by employment (frequencies and percentages)

\begin{tabular}{|c|c|c|c|c|c|c|c|c|c|c|c|c|c|c|}
\hline \multirow[b]{3}{*}{ Types of employment } & \multirow[b]{3}{*}{ Number } & \multirow[b]{3}{*}{$\%$} & \multicolumn{6}{|c|}{ Health related outcomes } & \multicolumn{6}{|c|}{ Health problems } \\
\hline & & & \multicolumn{2}{|c|}{$\begin{array}{l}\text { Job } \\
\text { dissatisfaction }\end{array}$} & \multicolumn{2}{|c|}{ Absenteeism } & \multicolumn{2}{|l|}{ Stress } & \multicolumn{2}{|l|}{ Fatigue } & \multicolumn{2}{|c|}{ Backache } & \multicolumn{2}{|c|}{ Muscular pains } \\
\hline & & & Number & $\%$ & Number & $\%$ & Number & $\%$ & Number & $\%$ & Number & $\%$ & Number & $\%$ \\
\hline Permanent employment & 10501 & 69.3 & 1138 & 10.9 & 2643 & 25.2 & 3051 & 29.5 & 1855 & 17.7 & 3010 & 28.7 & 1774 & 16.9 \\
\hline full time & 8420 & 55.6 & 950 & 11.5 & 2159 & 25.6 & 2484 & 29.5 & 1516 & 18.0 & 2448 & 29.1 & 1450 & 17.2 \\
\hline part time & 2081 & 13.7 & 188 & 9.2 & 484 & 23.3 & 567 & 27.2 & 339 & 16.3 & 562 & 27.0 & 324 & 15.6 \\
\hline Small employers & 923 & 6.1 & 96 & 10.6 & 160 & 17.3 & 317 & 34.3 & 238 & 25.8 & 287 & 31.1 & 179 & 19.4 \\
\hline Sole traders & 1836 & 12.2 & 327 & 17.9 & 290 & 15.8 & 567 & 30.9 & 479 & 26.1 & 635 & 34.6 & 480 & 26.1 \\
\hline full time & 1479 & 9.8 & 264 & 18.0 & 242 & 16.4 & 478 & 32.3 & 403 & 27.2 & 522 & 35.6 & 399 & 27.0 \\
\hline part time & 357 & 2.4 & 63 & 17.6 & 48 & 13.4 & 89 & 24.9 & 76 & 21.3 & 113 & 31.7 & 81 & 22.7 \\
\hline Precarious & 1886 & 12.5 & 377 & 20.1 & 430 & 22.8 & 422 & 22.4 & 401 & 21.3 & 576 & 30.5 & 380 & 20.1 \\
\hline Fixed term, full time & 979 & 6.5 & 191 & 20.0 & 264 & 27.0 & 239 & 24.4 & 229 & 23.4 & 311 & 31.8 & 218 & 22.3 \\
\hline Fixed term, part time & 417 & 2.8 & 72 & 17.4 & 75 & 18.0 & 73 & 17.5 & 69 & 16.5 & 102 & 24.5 & 62 & 14.9 \\
\hline Temporary, full time & 302 & 2.0 & 68 & 22.5 & 59 & 19.5 & 65 & 21.5 & 69 & 22.8 & 101 & 33.4 & 64 & 21.2 \\
\hline Temporary, part time & 188 & 1.2 & 46 & 25.0 & 57 & 22.0 & 45 & 23.9 & 34 & 18.1 & 62 & 33.0 & 36 & 19.1 \\
\hline Total & 15146 & & 1938 & 12.8 & 3523 & 23.3 & 4357 & 28.8 & 2973 & 19.6 & 4508 & 29.8 & 2813 & 18.6 \\
\hline
\end{tabular}


Job dissatisfaction

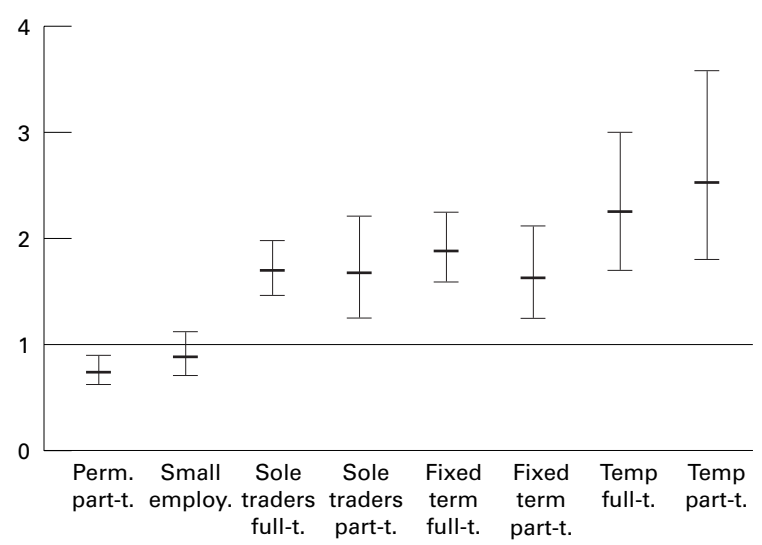

Fatigue

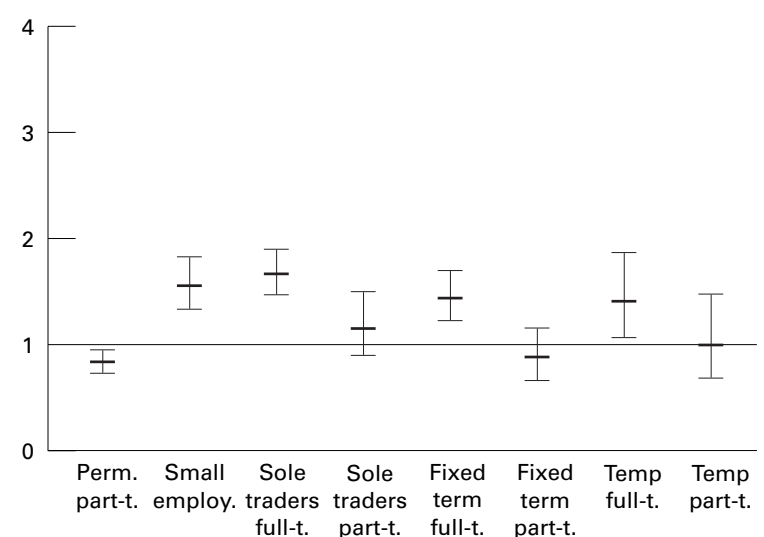

Stress

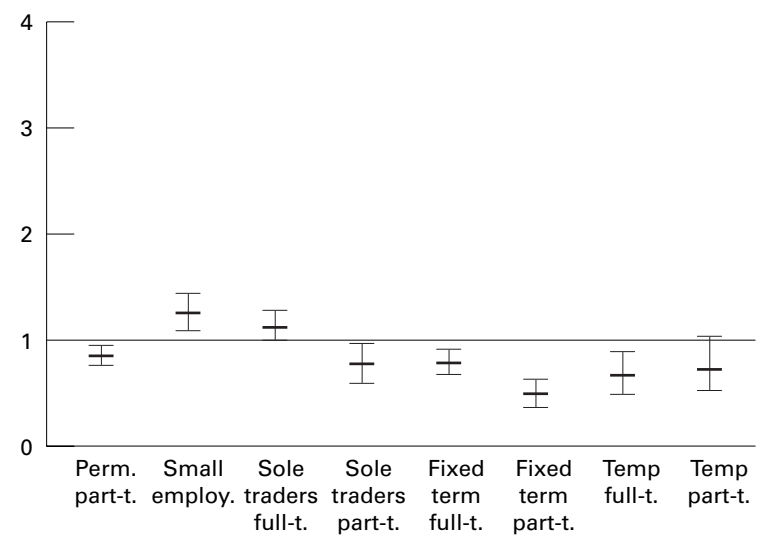

Absenteeism

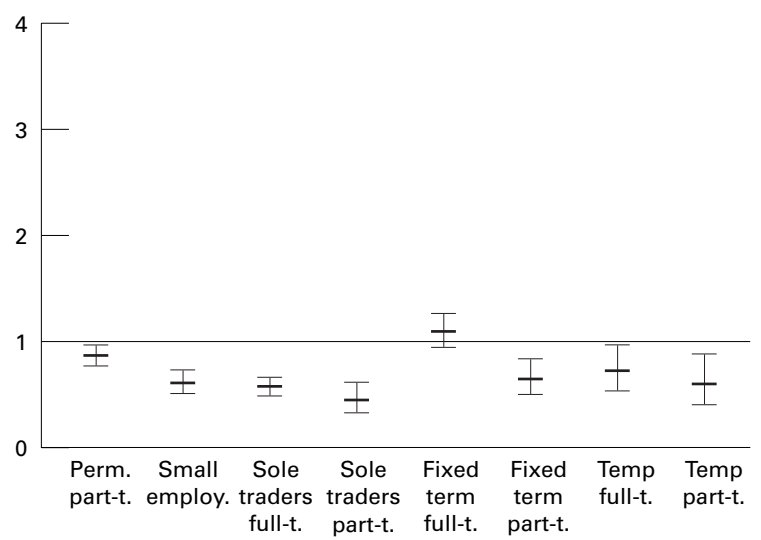

Backache

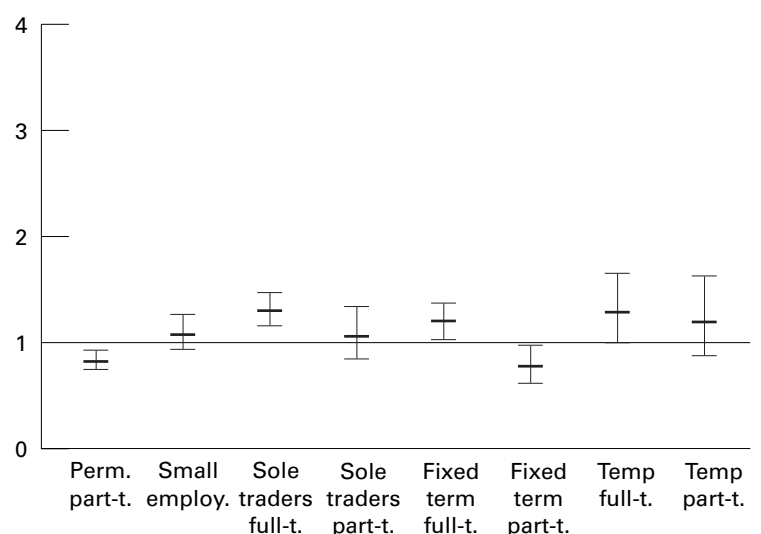

Muscular pains

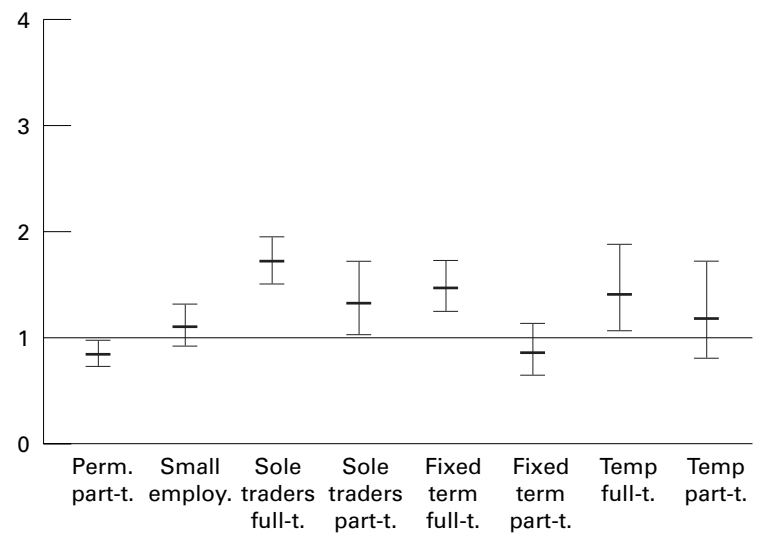

Figure 1 Age and gender adjusted odds ratios (and 95\% CI) of each outcome by employment categories (full time permanent employment as the reference category).

dissatisfaction, fatigue, backache and muscular pains than those in permanent employment. On the other hand, reported percentages of absenteeism and stress were generally higher in those with permanent employment than in those with precarious employment. Small employers reported high percentages of stress and fatigue, but absenteeism was relatively low. Sole traders generally reported high percentages of all outcomes, except for absenteeism, which was low. For each type of employment (except temporary contracts), full time workers tended to report worse health outcomes than part time workers. Among persons in tempo- rary contracts, differences between part time and full time workers in health outcomes were not consistent for the six indicators studied.

Age and gender adjusted odds ratios (OR) for each indicator by type of employment are shown in figure 1. Patterns observed after age and gender adjustment were generally consistent with the patterns described above for unadjusted proportions. Sole traders and employees in precarious employment (fixed term and temporary contracts) were more likely to report job dissatisfaction than full time permanent workers. The strongest associations were observed for temporary workers (part time OR 2.52 95\% CI: 1.79, 

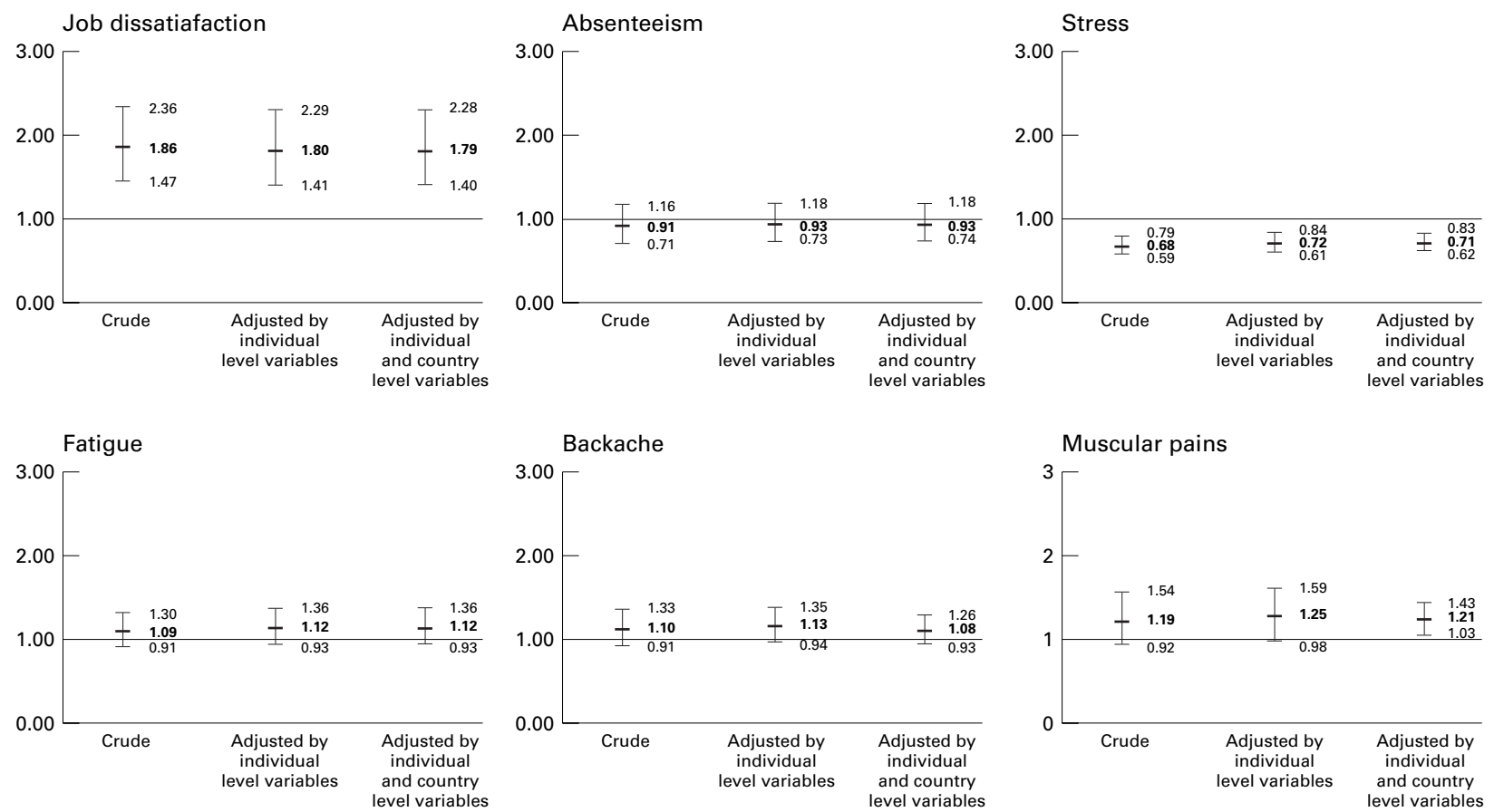

Figure 2 Odds ratios (and 95\% CI) of each outcome in precarious compared with permanent employment, adjusted for individual level (age and gender) and coutry level variables (unemployment, social protection, Gross National Product, and temporary contracts).

3.55) full time OR $2.2595 \%$ CI: 1.70, 2.97). With the exception of full time fixed term contracts, all types of employment showed significant lower levels of absenteeism than permanent full time contracts with ORs ranging from 0.45 (95\% CI: $0.33,0.61)$ for part time sole traders to 0.87 (95\% CI: $0.77,0.98)$ for part time permanent employments. Findings for stress were somewhat inconsistent: small employers and full time sole traders were significantly more likely than full time permanent workers to report increased stress, whereas part time sole traders, fixed term contracts and temporary contracts were significantly less likely to report stress.

Significantly higher levels of fatigue were documented for small employers (OR: 1.55; 95\% CI: $1.32,1.81$ ), full time sole traders (OR: 1.67; 95\% CI: $1.47,1.89$ ), full time fixed term workers (OR: 1.44; 95\% CI: 1.23, 1.69), and full time temporary workers (OR: $1.42 ; 95 \%$ CI: 1.07, 1.86). Full time sole traders, full time temporary workers, and full time fixed contract workers were also more likely to report backache and muscular pain than permanent full time workers (OR ranging from 1.18 to 1.66). Additional adjustment for the other individual level variables investigated (see table 1) did not substantially change these results (data not shown). Patterns for four employment categories (permanent, precarious, small employers and sole traders) were approximately similar across countries (results not shown).

The country level variables investigated were significantly heterogeneous across countries: unemployment varied from $2.9 \%$ for Luxembourg to $23 \%$ for Spain, social protection benefits varied from $15.5 \%$ for Greece to $40 \%$ for Sweden, Gross National Product per capita ranged from $11710 \mathrm{ppp}$ for Greece to 37930 ppp for Luxembourg, and temporary contracts varied from 6\% for Belgium to 33\% for Spain. Countries with high percentages of unemployment and temporary contracts and low percentages of social protection benefits and Gross National Product presented the highest percentages of precarious employment.

In multilevel models there was evidence of significant variation in intercepts (after controlling for type of employment and individual level variables) and in slopes associated with precarious employment across countries for the indicators studied. However, there was no consistent evidence of a contextual effect of country variables on the outcomes or of interaction between precarious employment and the country level variables studied. Associations of precarious employment with the outcomes remained virtually unchanged after adjustment for country level variables. Figure 2 shows OR of the indicators of interest in precarious compared with permanent employment before and after adjustment for age, gender, and country level variables. Additional adjustment for other individual level variables did not substantially modify the results.

\section{Discussion}

This study is the first to examine the relations between various types of employment and six health related indicators for all 15 member states of the EU. As the Second European Survey on Working Conditions was not specifically designed to assess the associations between types of employment and health indicators across countries, findings are preliminary and should be considered with caution.

A number of potentially important methodological limitations should be considered in interpreting our results. Firstly, this study has faced the problems inherent in many large scale 
international comparative studies with limited resources. Sample sizes in individual countries were not very large and response rates showed a large amount of variation (ranging from 35\% in Denmark to $81 \%$ in Austria). This limited our ability to conduct country specific analyses. Secondly, the health related indicators available were necessarily crude measures, as were many of the individual level covariates. For example, job satisfaction is not a direct measure of health status, and healthabsenteeism may be a poor proxy for health outcomes. The remaining health indicators were measured with very simple and crude indicators. The use of these measures may have limited our ability to detect significant associations. Likewise, measurement error in the individual level covariates may have limited our ability to control for these variables in adjusted analyses. Thirdly, there is no strong guarantee that the different types of employment categories were similar in the different countries and no agreement on the use of types of employment categories has been reached among researchers.

Four major dimensions have been mentioned in the process of defining precariousness: unstable jobs, low work control, low social or legal protection, and low income levels. ${ }^{23}$ According to the European Foundation, which defined precarious workers as those who felt insecure about their job or had a temporary or fixed term contract, almost $30 \%$ of European employed workers were in a precarious work situation. ${ }^{24}$ We used a more restrictive definition that only included those with temporary or fixed term contracts, which comprises $12.5 \%$ of total employment in the EU and $15 \%$ of paid employment. However, no studies have assessed the homogeneity of these categories across countries. This misclassification of employment category (if non-differential) may have biased our estimates towards the null. It is also important to note that the health effects of different types of employment categories may differ by gender. However, gender differences were not specifically examined in these analyses. Finally, because of its cross sectional nature, this study cannot firmly establish causal relations, and the "reverse causation" hypothesis cannot be categorically ruled out.

Despite its limitations, our study did find suggestive patterns worthy of further exploration. Job dissatisfaction was consistently and positively associated with precarious employment while absenteeism and stress were generally negatively associated with precarious employment. Fatigue, backache and muscular pains also tended to be positively associated with precarious employment, particularly with full time precarious employment. Sole traders and small employers generally showed adverse indicators but low absenteeism. Associations between types of employment and health indicators almost always persisted after adjusting for several working condition variables at the individual level. Our ability to examine covariates related to the work environment as mediators or confounders of the associations observed is limited by the measures of these variables available. However, to the extent that we could adequately control for them, our findings suggest that employment contracts may have an independent effect on selected indicators of perceived health independently of the working conditions we measured. In addition, full time workers generally reported worse health outcomes than part time workers except for those in temporary contracts. This finding is consistent with the fact that part time work in permanent employments may have been chosen voluntarily whereas part time work that goes with unstable employment may add to work insecurity and to ill health.

It is interesting to consider how the patterns observed for the six outcomes studied are interrelated. Various studies have pointed out that sickness absence may reflect not only physical health, but also an employee's perception of his or her health - that is, that it can be thought of as a coping behaviour in response to illness (a subjective state, a psychological awareness of dysfunction) rather than physical disease..$^{25}$ In our analyses, self perceived health was not directly associated with work absenteeism. Overall, permanent employments presented low levels of job dissatisfaction and health problems (that is, fatigue, backache and muscular pains) and moderate levels of stress, but absenteeism was high. This finding, which is likely to be attributable to the definition of absenteeism used in the Survey, deserves further exploration. A recent European report showed a large variation in absenteeism across countries, which may partly be attributable to its different definition across countries. ${ }^{27}$

In contrast, despite showing high levels of adverse health indicators, sole traders and small employers reported low levels of absenteeism. Previous research conducted in a population of non-industrial civil servants, where the overwhelming majority of workers were permanent, reported a strong inverse association between sickness absence and grade of employment and identified high levels of job dissatisfaction as one of the risk factors involved. ${ }^{25}{ }^{28}$ We found that precarious workers, presented both high levels of job dissatisfaction and low levels of absenteeism. Although no definitive explanations can be put forward for these findings at this point, differences in job security may obviously play an important part in explaining these differences.

We also found that reported job dissatisfaction and reported stress followed quite opposite patterns in most employments. For example, precarious workers showed high levels of job dissatisfaction and low stress, while small employers reported low job dissatisfaction but high levels of stress. Although reasons for these differences are unclear, the unexpected association of low control with low reported stress documented in a previous report based on these data ${ }^{14}$ may help explain the opposite patterns observed for job dissatisfaction and stress. These issues need to be investigated further in studies with more rigorous measurements.

Cross country comparisons of the associations are difficult for several reasons: firstly, the 
meaning and characteristics of the employment categories may differ for each country; secondly, different degrees of selection bias may be present from country to country because of differences in response rates; and thirdly, the country specific relations between employment and health could not be studied for the full nine categories because of sample size limitations. Nevertheless, to the extent that it could be investigated, relations between the four employment categories and health were generally similar across countries. There was no evidence that country level variables modified the effects of precarious employment. Moreover, associations between employment categories and the health indicators remained virtually identical after country level variables were included in the models as main effects, suggesting that types of employment are related to the outcomes independently of these country level variables. However, because the number of countries available for analysis was small (15), a limited number of country level variables were available, and data on other (and perhaps more pertinent) geographical areas (such as regions) were unavailable, we cannot conclude from these results that country level or regional characteristics related to economic conditions and social policy do not modify the relation between type of employment and health outcomes.

The global economy is generating a new set of job insecurities for workers. As the frontier between precarious employment and unemployment is becoming blurred, research needs to move away from the comparison of unemployed versus employed towards a more dynamic characterisation of unemployed and underemployed workers versus workers with stable jobs. Although underemployment and precarious employment share some of the characteristics of unemployment, and it seems plausible that they could produce similar adverse effects on health, information on the potential impact of underemployment on health is very limited. ${ }^{2}$

To our knowledge this is one of the first studies to examine the associations of various types of employment with a series of health related indicators. However, our findings need to be refined and replicated before they are taken as causal evidence. Studies with improved measurement and more specific hypotheses are needed. We suggest that future research in this area should take into account the following issues: the need to use a standardised definition of the categories of underemployment, the need to diversify, standardise and improve the health indicators examined, the need to implement more potent epidemiological designs that integrate individual and ecological variables, and the need to include information on social security systems, incapacity benefit schemes, and other socioeconomic features at the country or regional level. The study of the potential effects of underemployment and precarious employment on health is a public health need and a challenge for researchers.
The authors thank the anonymous reviewers for their helpful suggestions.

Funding: European Foundation for the Improvement of Living and Working Conditions, Dublin (contract 97-3030-74). Conflicts of interest: none.

1 Janlert U. Unemployment as a disease and diseases of the unemployed. Scand f Work Environ Health 1997;23 (suppl 3):79-83.

2 Dooley D, Fielding J, Levi L. Health and unemployment. Annu Rev Public Health 1996;17:449-65.

3 Shortt SED. Is unemployment pathogenic? A review of current concepts with lessons for policy planners. Int $\mathcal{f}$ Health Serv 1996;26:569-89.

4 Benavides FG, García AM, Sáez-Lloret I, et al. Unemployment and health in Spain: the influence of socio-economic environment. Eur F Public Health 1994;4:103-7.

5 Marshall A. Secuelas del paro: El nuevo papel del trabajo temporal y del trabajo a tiempo parcial en Europa occidental. In: Rodgers G, Rodgers J, eds. El trabajo precario en la regulación del mercado laboral. Madrid: Ministerio de Trabajo y Seguridad Social, 1992:43-90.

6 Letorneux V. Precarious employment and working conditions in the European Union. European Foundation for the Improvement of Living and Working Conditions. Luxembourg: Office for Official Publications of the European Communities, 1997.

7 Burchell B. The effects of labour market position, job insecurity, and unemployment on psychological health. In: Gallie D, Marsh C, Vogler C, eds. Social change and the experience of unemployment. Oxford: Oxford University Press, 1994:188-212.

8 Bartley M, Montgomery S, Cook D, et al. Health and work insecurity in young men. In: Blane D, Brunner E, Wilkinson R, eds. Health and social organization. London: Routledge, 1996:255-71.

9 Platt S, Pavis S, Akram G. Changing labour market conditions and health: a systematic literature review (1993-1998). Luxembourg: Office for Official Publication of the European Communities, 1999

10 Boix P, Orts E, López MJ, et al. Trabajo temporal y siniestralidad laboral en España en el período 1988-1995. Cuadernos de Relaciones Laborales 1997;11:275-319.

11 François $M$, Lievin D. Existe-t-il un risque spécifique aux François $M$, Lievin $D$. Existe-t-1l un risque specifique aux
emplois précaires? Communication au XXVIII congrès de la Self, 1993. In: François M. Précarité et travail. Quels effets sur les conditions d'emploi et de sécurité?. Travail 1993/94;30:44.

12 Diez-Roux AV. Bringing context back into epidemiology: variables and fallacies in multilevel analysis. Am $\mathcal{F}$ Public Health 1998;88:216-22.

13 Paoli P. Second European Survey on Working Conditions. Dublin: European Foundation for the Improvement of Living and Working Conditions, 1997.

14 Benavides FG, Benach J. Precarious employment and health-related outcomes in the European Union. Luxembourg: Office for Official Publication of the European Communities, 1999 .

15 EUROSTAT. Basic statistics from the European Union. 33rd ed. Luxembourg: Statistical Office for the European Communities, 1996.

16 EUROSTAT. Statistiques en bref. Population et conditions EUROSTAT. Statistiques en bref. Population
sociales. 1997. Luxembourg: Eurostat, 1997.

17 EUROSTAT. Facts through figures. Luxembourg: Office for EUROSTAT. Facts through figures. Luxembourg: Office for
Official Publications of the European Communities, 1996. 18 The World Bank. The World Bank atlas 1997. Washington, DC: The World Bank, 1997.

19 Duncan C, Jones K, Moon G. Context, composition and heterogeneity: using multilevel models in health research. Soc Sci Med 1998;46:97-117.

20 Bryk AS, Raudenbush SW. Hierarchical linear models. Newbury Park: Sage Publications, 1992

21 Green SB, Salkind NJ, Akey TM. Using SPSS for Windows: analyzing and understanding data. Upper Saddle River, NJ: Prentice Hall, 1997.

22 Bryk AS, Raudenbush SW, Congdon RT Jr. Hierarchical linear and nonlinear modeling. Chicago: SSI Scientific Software International, 1996.

23 Rodgers G. El debate sobre el trabajo precario en Europa Occidental. In: Rodgers G, Rodgers J, eds. El trabajo precario en la regulación del mercado laboral. Madrid: Minisprecario en la regulación del mercado laboral. Madrid:

24 Dhont S, Houtman I, the Working Group of the European Foundation for the Improvement of Living and Working Conditions. Indicators of working conditions in the European Union. Luxembourg: Office for Official Publications of the European Communities, 1997.

25 Marmot M, Feeney A, Shipley M, et al. Sickness absence as a measure of health status and functioning: from the UK Whitehall II study. $\mathcal{F}$ Epidemiol Community Health 1995;49: 124-30.

26 Kristensen TS. Sickness absence and work strain among Danish slaughterhouse workers: an analysis of absence from work regarded as coping behaviour. Soc Sci Med 1991;32:15-27.

27 Gründemann RWM, van Vuuren CV. Preventing absenteeism at the workplace. Dublin: European Foundation for the at the workplace. Dublin: European Foundation for the
Improvement of Living and Working Conditions, 1997 .

28 North F, Syme SL, Feeney A, et al. Explaining socioeconomic differences in sickness absence: the Whitehall II study. BMF 1993;306:361-6. 